\title{
La política de la protesta en regímenes autoritarios: síntesis crítica
}

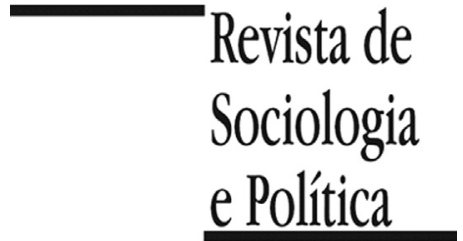

DOI 10.1590/1678-987317266506

\section{Felipe Sánchez Barría id}

\begin{abstract}
RESUMEN Introducción: A través de una revisión crítica de la literatura reciente, el ensayo explora la relación entre protesta contenciosa y regímenes autoritarios, y examina las dinámicas y consecuencias que emergen durante el conflicto político. Métodos: Para lo anterior se discuten tres elementos que los especialistas han identificado como los principales en esta relación: oportunidades y amenazas políticas; ciclos de protesta y sostenibilidad de los movimientos sociales; y la relación entre violencia estatal y acción colectiva. Resultados: La recurrencia de la protesta en regímenes represivos muestra la capacidad de la sociedad civil para articular este tipo de acciones contenciosas. Discusión: No obstante, las trayectorias y resultados dependen, por una parte, de las características políticas del régimen y la competencia del gobierno para responder a los desafíos colectivos; $y$, por otra parte, de la capacidad de los oponentes de montar ciclos de protestas densos en participación durante un periodo significativo, del tipo de tácticas adoptadas, y de la capacidad de adaptación y resiliencia a la violencia estatal.
\end{abstract}

PALABRAS CLAVE: protesta; autoritarismo; política contenciosa; régimen político; represión.

Recibido en el 31 de Agosto de 2016. Aprobado en el 13 de Abril de 2017.

\section{Introducción ${ }^{1}$}

${ }^{1}$ Este trabajo forma parte de mi tesis doctoral en sociología sobre Ciclos de Protestas en Regímenes Autoritarios. Esta investigación se desarrolla gracias a la Beca Doctorado Nacional de la Comisión Nacional de Investigación Científica y Tecnológica (Conicyt). Esta tesis también se encuentra patrocinada por el Centro de Estudios de Conflicto y Cohesión Social, COES (FONDAP 15130009). Agradezco a Nicolás Somma, director de esta tesis, por sus comentarios y sugerencias. Finalmente, agradezco los comentarios y sugerencias de los dictaminadores anónimos de Revista de Sociologia e Política.
$\mathrm{E}$ n 2011, la revista Times nombró personaje del año al "Manifestante" ("The Protester"). La razón de ello es que dicho año se produjeron una serie de masivas olas de protestas en varias partes del mundo. Desde Nueva York, con el movimiento "Occupy Wall Street", hasta España con "Los Indignados"; también en Chile con la movilización estudiantil, pasando por Brasil con las manifestaciones en contra del gobierno, hasta México con el movimiento "Yosoy132". Algunas con más éxito que otras, cada una de estas movilizaciones se caracterizó por la enorme convocatoria y la gran presión que ejercieron sobre sus respectivos gobiernos para conseguir reformas de todo tipo: económicas, educativas o por más espacios de participación. Así, siguiendo la tesis de Pippa Norris (2002) en su estudio sobre el activismo político contemporáneo, el declive en las formas tradicionales de participación cívica en el mundo occidental -como el voto o la militancia en un partido político- no significó un declive en el compromiso político de los ciudadanos. Por el contrario, sólo se confirmó un cambio en los modos de participación, siendo la protesta pública la principal forma que habría adquirido este nuevo activismo, especialmente entre los grupos más educados de sociedades pos-industriales.

Sin embargo, lo que realmente hizo que el año 2011 fuera el año del "manifestante" no fueron tanto las movilizaciones en las principales ciudades de Estados Unidos o Europa occidental, sino el levantamiento de poderosos movimientos sociales en Medio Oriente y el norte de África, los cuales desafiaron a regímenes autoritarios altamente represivos y consolidados por décadas. Comenzando en Túnez, cuando a fines de 2010 un vendedor callejero de 26 años se encendió fuego como protesta por haberle sido arrebatados su mercadería y sus ahorros, dando paso una serie de masivas movilizaciones que terminarían con la dimisión del dictador Zine el Abidine Ben Ali, que gobernaba el país desde 1987. Luego, lo seguiría Egipto y la caída de Hosni Mubarak con más de 30 años en el poder; y también en Libia donde después de una fuerte represión por parte de las fuerzas leales al régimen, los rebeldes lograrían tomar 
${ }^{2}$ Las referencias fueron tomadas de la versión digital de Times de diciembre de 2011.

http://content.time.com/time/s pecials/packages/article/0,288 04,2101745 2102139,00.html (consultado en el 22/08/2016).

\footnotetext{
${ }^{3}$ En este trabajo la movilización social que se estudia es aquella opositora al régimen autoritario. Esta aclaración es importante, ya que la sociedad civil no necesariamente se moviliza políticamente en pro de reformas y/o valores democráticos. Existen casos donde la sociedad civil se organiza para promover el odio hacia otros grupos (ej. Ku Klux Klan) o para promover golpes de Estado. A modo de ejemplo, en 2002, Hugo Chávez sufrió un intento de golpe promovido por las principales organizaciones patronales del país. Casi 30 años antes, en Chile los principales gremios industriales, comerciales y agrícolas (con ayuda de la CIA) estimularon una dura y persistente oposición al gobierno de Salvador Allende hasta su derrocamiento en 1973. Una discusión sobre esta "mala sociedad civil" puede encontrarse en Chambers y Kopstein (2001) y Encarnación (2002).
}

control sobre el país, capturar al dictador Gadafi (42 años en el poder) y ejecutarlo. Otros países de larga tradición autoritaria como Argelia, Yemen, Siria, El Líbano, etc., también serían escenario de estas movilizaciones populares de gran escala, exigiendo mejores condiciones de vida $\mathrm{y}$, sobre todo, democracia $^{2}$.

La "primavera árabe" como fueron conocidas estas masivas protestas se caracterizaron no sólo porque ocurrieron lejos de sociedades pos-industriales con viejas tradiciones democráticas, sino en países conocidos por sus trayectorias autoritarias y represivas, y donde la protesta pública estaba muy alejada de ser el "mainstream" del activismo cívico. Además, quienes protagonizaron estas manifestaciones no eran aquellos sectores educados, con más recursos y con mayor capital social, sino amplios grupos de agraviados cansados de los abusos de los dictadores, como fue el caso de aquel vendedor callejero tunecino que se quemó a lo bonzo como protesta en contra del abuso de la policía y que encendió a todo el país a movilizarse en contra del dictador Ben Ali.

Estos acontecimientos, entonces, desafían ciertas nociones predominantes sobre la emergencia de los movimientos sociales contemporáneos. Junto con el estudio de Norris ya citado, más recientemente Weldon \& Dalton (2014) analizaron el nexo entre los contextos institucionales y las características individuales para testar distintas hipótesis rivales sobre la protesta, e igualmente encontraron que es en las sociedades posindustriales donde aquellos individuos con mayores y más diversos recursos son los más propensos a participar en este tipo de actividades. Esto sería así porque las democracias consolidadas y afluentes suelen tener una sociedad civil más robusta y con un capital social más amplio, facilitando la organización y participación en diversas formas de acción política (ver también Dalton, Van Sieckle \& Weldon 2010; Welzel, Inglehart \& Deutsh 2005).

Entonces ¿cómo es posible explicar la emergencia de movimientos de protesta en contextos no-democráticos, cuya sociedad civil ${ }^{3}$ se ve continuamente reprimida y amenazada ante cualquier iniciativa de actividad política? Precisamente, este trabajo explora la relación entre protesta y gobiernos autoritarios, y examina qué consecuencias tiene el conflicto que surge de esta relación tanto para el régimen y su supervivencia, como para los movimientos sociales y sus objetivos. Para lo anterior se hace una revisión crítica de los debates existentes en literatura más reciente dedicada al estudio de este asunto, centrando la atención en tres elementos que los especialistas han identificado como los principales para entender las dinámicas y posibles trayectorias entre protesta y autoritarismo: las oportunidades y amenazas políticas; los ciclos de protesta y la sostenibilidad de los movimientos sociales; y la relación entre violencia represiva y protesta.

Durante largo tiempo, los estudiosos de los movimientos sociales y la protesta pública, y aquellos especialistas interesados en los autoritarismos y los procesos democratizadores, corrieron por carriles separados. Mientras la escuela sociológica norteamericana de la política contenciosa desarrolló gran parte de sus investigaciones en contextos democráticos como Estados Unidos o Europa occidental; los politólogos especialista en gobiernos autoritarios se enfocaron en el rol de las élites y los conflictos al interior del régimen como la principal causa de desestabilización y quiebre de éstos, poniendo en una posición subordinada al rol que podían jugar los movimientos de protesta sobre la política del régimen.

No obstante, en los últimos años, ha aumentado el interés y los estudios que han buscado reunir ambas áreas de estudios con el objetivo de entregar un mejor entendimiento de las dinámicas de la política contenciosa y la acción colectiva en regímenes autoritarios. Estos trabajos han permitido abrir preguntas de pro- 
fundo interés para los especialistas en autoritarismos, y también para aquellos preocupados por la acción colectiva contenciosa, extendiendo la comprensión que se tenía sobre ambos fenómenos. Por ejemplo, desde la perspectiva del cambio de régimen político, estos estudios lograron observar una serie de complejas relaciones que se daban entre aquellas amenazas al régimen de tipo horizontal (élites) y aquellas de tipo vertical (movimientos sociales), lo que permitió la apertura a nuevas preguntas respecto de qué tipo de dinámicas facilitan los procesos de desestabilización y caída de los autoritarismos, y bajo qué contextos uno u otro tipo de amenazas podía prevalecer. Del mismo modo, la atención a desafíos populares problematizó el uso de la violencia represiva en contextos no-democráticos. Como se verá más adelante, la relación entre represión y protesta puede ir variando constantemente dentro de un mismo régimen, no sólo debido a la capacidad de coerción del régimen, sino también al tipo de campaña contenciosa a la que el gobierno debe hacer frente.

Del mismo modo, esta reciente literatura ha avanzado de forma importante en la comprensión de la acción colectiva, en particular en lo que respecta las trayectorias y los resultados de los movimientos de protesta. Aunque el modelo del proceso político, dominante entre los especialistas de la política contenciosa, ha explicado de modo bastante convincente cómo la protesta puede surgir y expandirse, menos consenso y desarrollo ha habido sobre cuáles son las dinámicas que siguen estos movimientos una vez que se han activado y que factores explicarían sus posibles éxitos o fracasos. En cambio, al ser una preocupación fundamental el asunto de la desestabilización y/o el quiebre de los gobiernos autoritarios, estos estudios se han preocupado por entender en qué condiciones los movimientos pueden seguir trayectorias que aumenten sus chances de éxitos en derrocar al régimen o, al menos, conseguir reformas importantes. Entre los aspectos adelante discutidos en relación con esto se encuentra el asunto de los "ciclos de protesta" y las características que favorecen una rápida y sostenida difusión de la protesta, así como la elección del tipo de acciones -violentas o no violentas- que prefieren los opositores, y el modo en que hacen frente a la represión estatal.

Cada uno de estos temas se discute en detalle a continuación. La primera sección es una revisión del modelo del proceso político o de oportunidades políticas. En esta parte se exponen los principales elementos que componen este enfoque y se discuten algunos límites para explicar la protesta en regímenes autoritarios. A continuación, se analizan los regímenes autoritarios, algunas de sus principales características y algunos tipos de autoritarismos que los especialistas han identificado. Ya en la tercera sección se revisa con más detalle el problema de la protesta contenciosa en regímenes autoritarios con base en la literatura más reciente que ha examinado este tema. A partir de los problemas específicos tratados, así como de la evidencia empírica presentada por los especialistas, se discuten las ventajas explicativas como los límites analíticos que se observan en cada uno de estos trabajos. Como ya se adelantó, los principales temas abordados en esta sección son las oportunidades y amenazas políticas; los ciclos de protesta y la sostenibilidad de los movimientos; y finalmente la relación entre violencia represiva y acción colectiva. A pesar de que cada uno de estos temas se analizan en secciones diferentes, las relaciones entre ellos son continuas de tal forma que casi no es posible abordarlos de forma exclusiva. Por lo mismo, constantemente se hará mención a los otros temas examinados en las demás secciones a fin de darle mayor cohesión a los asuntos que se están discutiendo.

Asimismo, los enfoques propuestos por estas investigaciones se discutirán comparando los diferentes casos analizados por estos especialistas junto con otros ejemplos que los autores no han considerado con el objetivo de poner en tensión los modelos conceptuales. En este sentido, es interesante notar la 
presencia de un claro sesgo geográfico en la selección de casos. La mayoría de estos trabajos examinan episodios de política contenciosa en autoritarismos que han ocurrido en Europa del Este, en Asia o en África. Mucha menos atención ha sido puesta a las experiencias autoritarias de América Latina, un continente que fue testigo de feroces dictaduras militares, así como de notables movimientos opositores (algunos violentos, otros no), pero donde la acción política colectiva dejó aprendizajes políticos permanentes, y que por tanto deben volver a ser analizados a la luz de los avances que ha mostrado la literatura más reciente que en este trabajo se expone. Sólo Guatemala y El Salvador han sido tratados con mayor detención por esta literatura, no obstante, debido a lo señalado más arriba también se recurre a otros casos como el chileno con Pinochet o el mexicano con el PRI, dos autoritarismos muy disímiles entre sí pero también frente a los casos que ocuparon los especialistas para sus estudios.

La última sección corresponde a los comentarios finales. En esta parte se espera realizar un balance de la revisión realizada y destacar los aspectos más sobresalientes de los resultados obtenidos por estos estudios, así como de la pertinencia de las herramientas conceptuales y los modelos explicativos desarrollados.

\section{El modelo del proceso político para explicar la emergencia de la protesta contenciosa}

Una característica fundamental de la acción colectiva contenciosa es la enorme variabilidad que se observa en su emergencia y posteriores dinámicas. Esto ha desafiado constantemente los modelos explicativos y el desarrollo conceptual vinculados a la literatura interesada en estos asuntos (Davenport 2005, Opp 2009). No obstante, los especialistas han logrado identificar al menos tres grupos de factores explicativos sobre la acción colectiva y la política contenciosa: la estructura de oportunidades políticas, las estructuras de movilización y los procesos enmarcadores (Davenport 2005; McAdam, McCarthy \& Zald 1996; Tarrow 1998). Cada uno de los factores mencionados anteriormente pone énfasis en diferentes aspectos considerados por los estudiosos como necesarios para dar cuenta de las acciones de protesta. Las oportunidades políticas se refieren a aquellas "dimensiones del ambiente político que entregan incentivos para la acción colectiva, afectando las expectativas de éxito o fracaso" (Tarrow 1998, pp.76-77). Por su parte, las estructuras de movilización hacen referencia a las organizaciones formales e informales de los movimientos, las conexiones entre ellas y el modo en que logran ampliar sus bases (McCarthy \& Zald 1977). $\mathrm{Y}$ finalmente el "framing" o los procesos enmarcadores estudia aquellos "esquemas de interpretación" que otorgan significados compartidos a diferentes eventos en la vida de las personas, permitiendo organizar la experiencia y guiar la acción colectiva en torno a dichos esquemas (Snow et al., 1986).

No obstante, ha sido el enfoque centrado en las oportunidades políticas el que ha dominado la literatura especializada desde de la década de 1980 (Opp 2009 , p.162). Esta línea teórica, también conocida como "modelo del proceso político", no sólo hace referencia a aspectos internos de los movimientos y sus organizaciones para dar cuenta de la acción colectiva, también considera factores externos y contingentes en su modelo explicativo. Inicialmente Tarrow (1998) identificó cuatro indicadores característicos en la estructura de oportunidades políticas: el acceso político pleno, las alineaciones inestables, las divisiones al interior de las élites y la existencia de aliados influyentes. Posteriormente McAdam, Tarrow y Tilly (2003; también Tilly 2001 y 2006; Tilly \& Tarrow 2015) incluyeron la existencia de múltiples centros de poder dentro del régimen político, la apertura a nuevos actores y el grado en el cual el régimen reprime o facilita las demandas colectivas. Estos estudiosos vieron la necesidad de incluir de modo explícito en su enfoque conceptual el rol que 
cumplía el "régimen político". En este modelo, un régimen político está formado por las relaciones entre gobiernos, actores políticos establecidos, actores políticos carentes de acceso rutinario a las instituciones, y actores políticos externos - incluido otros gobiernos (2001, p. 29). De tal modo que un cambio de régimen ocurre cuando se introducen nuevos actores, disminuye el poder de los miembros estables del régimen o se modifican las relaciones entre ellos. Siempre un cambio en el régimen implica necesariamente un cambio en las oportunidades y amenazas políticas (Tarrow 2013, p.280).

Considerar el tipo de régimen político era necesario en tanto la acción colectiva no sólo involucra a unos actores colectivos y un gobierno, sino a múltiples actores políticos y a la totalidad de las relaciones que se dan entre ellos en todos los niveles de la política. Esta inclusión si bien hizo más dinámico y flexible el modelo explicativo, también complejizó el panorama. Por ejemplo, la apertura a nuevos actores políticos y a la realización de demandas colectivas, así como la descentralización del poder político son características comunes en regímenes democráticos consolidados, en los cuales se regula no sólo la política institucional sino también el modo en el cual los actores pueden participar colectivamente. No es raro entonces que sea en países política y económicamente desarrollados, con democracias consolidadas e índices de desarrollo humano elevados, donde la protesta se ha convertido en una práctica política convencional entre los ciudadanos. Las hipótesis detrás de estos hallazgos es que en sociedades afluentes se presentan ciudadanos con mayores recursos tales como: cualificaciones educativas, tiempo, dinero, y habilidades cívicas, entre otros. Dichos recursos no sólo facilitarían materialmente la participación en actividades políticas, sino que la misma participación contribuiría al desarrollo y ampliación de los recursos, generando una sociedad civil robusta, activa y comprometida (Dalton, Van Sickle \& Weldon 2010; Brady, Verba \& Schlozman 1995).

Siguiendo esta línea, si la protesta se está convirtiendo en el "mainstream" de la participación política, entonces se abren al menos dos problemas explicativos importantes. Primero, ¿hasta qué punto es posible hablar de política contenciosa cuando se hace referencia a la protesta en países afluentes que han vuelto esta práctica una actividad rutinaria para los ciudadanos más educados? y, segundo, ¿cómo es posible explicar desde la perspectiva del proceso político la emergencia de la protesta en países cuyos regímenes obstaculizan la apertura de las oportunidades políticas señaladas anteriormente? Al respecto, los especialistas del modelo del proceso político han definido política contenciosa como:

"La interacción episódica, pública y colectiva entre los reivindicadores y sus objetivos, cuando: (a) al menos un gobierno es uno de los reivindicadores, objeto de las reivindicaciones o forma parte de las reivindicaciones, y (b) las reivindicaciones, en caso de ser satisfechas, afectarían los intereses de al menos de uno de los reivindicadores" (McAdam, Tarrow \& Tilly 2003, p.5).

Aunque útil, esta definición presenta ciertos límites al comparar democracias desarrolladas y regímenes autocráticos. La política trata fundamentalmente de la consecución de intereses y proyectos distintos y, muchas veces, conflictivos entre sí. Pero eso no la vuelve necesariamente contenciosa. Los trabajos de Norris y Dalton citados anteriormente muestran cómo los países con democracias consolidadas han logrado hacer de la protesta una actividad que forma parte de su régimen político, es decir, una actividad regulada en la cual las relaciones de poder están definidas y delimitadas, permitiendo su realización, sin que ello impida la consecución de los intereses reivindicados, ni tampoco una amenaza a la estabilidad del régimen. Como bien afirma della Porta \& Diani (2006, p.166), en sociedades industriales avanzadas, la acción política directa no carga con el estigma de la desviación, ni son vistas como acciones de 
orientaciones antisistema. La política se vuelve contenciosa cuando las acciones políticas llevadas a cabo por los actores colectivos tienen como objetivo precisamente "contestar" (contest) y desafiar al régimen que regula las relaciones de poder en el cual se encuentran inmersos. En otras palabras, lo contencioso tiene más que ver con los objetivos perseguidos que con las tácticas utilizadas (Schock 2005). Esta diferencia conceptual es fundamental, ya que, a diferencia de la protesta en democracias establecidas, las acciones colectivas en regímenes autoritarios usualmente se articulan con objetivos "radicales", es decir, buscan un cambio sustancial en el régimen político.

Lo anterior lleva a la segunda pregunta planteada más arriba, cómo es posible explicar, desde la perspectiva del proceso político, la protesta y la acción colectiva en países cuyos regímenes dificultan el mismo tipo de estructura de oportunidades políticas que en países con trayectorias democráticas fuertes. Al abordar el fenómeno de la acción colectiva y la política contenciosa en contextos no democráticos, se vuelve entonces aún más fundamental tener una caracterización lo más precisa del régimen en el cual se desarrolla la política. El modelo del proceso político ofrece un esquema bastante simple e intuitivo para clasificar el tipo de régimen, definido como una función de dos elementos clave: la capacidad del Estado y el alcance de la democracia (McAdam, Tarrow \& Tilly 2003). Mientras la primera característica hace referencia al grado de control tiene sobre las personas, recursos y actividades; la segunda describe el grado en el cual las personas sujetas a la autoridad del gobierno tienen igual derecho para elegir sus autoridades y recibir protección frente a una posible acción arbitraria por parte de los gobernantes (Tilly 2006, p.21). Evidentemente en cualquier régimen estos elementos son relativos, y el modo en el cual, eventualmente, se desarrolla la acción colectiva contenciosa depende de las combinaciones y los grados en los cuales se manifiestan estas características.

\section{Los regímenes autoritarios}

Los regímenes autoritarios corresponden aquellos donde el grado de democracia, como fue definido más arriba, es notoriamente bajo. Institucionalmente, esto se puede constatar en la inexistencia de instancias y/o procedimientos formales a través de los cuales las personas sean consultadas sobre los asuntos públicos de su país, y donde el Estado garantice que la integridad de quienes participan no estará en riesgo. Bajo esta definición es posible encontrar autoritarismos tan disímiles como el de la República Dominicana de Trujillo o el de Malasia bajo el gobierno de la Organización Nacional de Malasia Unida (ONMU). En el país caribeño, Rafael Trujillo gobernó desde 1931 a 1961 de forma implacable y violenta, dando origen a una de las dictaduras más sangrientas de América Latina en el siglo XX. El autoritarismo de Trujillo fue completamente personalista, a pesar de la existencia de un partido oficial. El culto a la personalidad se transformó en el único canal establecido a través del cual los sujetos podían obtener algún beneficio por parte del dictador (Derby 2009; Linz 1975).

Muy diferente es el caso de Malasia. Este país es dominado por un partido único y, desde su independencia en 1957, la OMNU ha gobernado sin contrapeso político hasta la actualidad sobre la base de elecciones regulares. Bajo este régimen es el partido -y no un líder personalista- el que establece los mecanismos y procedimientos en los que se darán las elecciones, así como quienes pueden participar ya sea como votantes o como oposición. Es lo que Levistky y Way (2010) han denominado un "autoritarismo competitivo", es decir un régimen donde "las instituciones democráticas formales existen y son vistas como el principal medio para ganar poder, pero en el cual el abuso del Estado 
por parte de los incumbentes los coloca en una posición de significativa ventaja frente a sus oponentes" (Levistky \& Way 2010, p.5). En este sentido, los procedimientos en este tipo de regímenes, aunque autoritarios, parecen ser mucho menos arbitrarios que en un régimen personalista, ya que tales procedimientos son conocidos y aceptados tanto por los miembros del partido como por aquellos que actúan en la oposición. A su vez, las elecciones en sistemas como el malayo, aunque ni democráticas ni libres ni justas, proveen información acerca del control del régimen sobre élites influyentes, sobre el apoyo popular, y sobre los críticos y las posibles fuentes de contestación. En palabras de Brownlee (2007, p.9) "las elecciones bajo autoritarismos tienden a revelar tendencias políticas antes que impulsarlas".

Ahora bien, respecto a la segunda dimensión a la que refiere Tilly en su esquema para clasificar los tipos de régimen político, tiene que ver con la capacidad del Estado. Esta dimensión hacer referencia al poder del régimen para establecer, definir e imponer los límites institucionales y la relación que la sociedad civil deberá establecer con dicha institucionalidad. Al igual que sucede con los niveles de democracia, la capacidad del Estado dentro del contexto del autoritarismo presenta una enorme variabilidad entre uno y otro caso. Al respecto, El Salvador es un buen ejemplo de autoritarismo con capacidad variable. Durante gran parte del siglo XX la política salvadoreña estuvo gobernada por militares de distintas facciones. En 1931, a causa de la grave crisis económica ocasionada por la caída de los precios del café producto de la Gran Guerra, el general Maximiliano Hernández derrocó al gobierno de Arturo Araujo, imponiendo un régimen extremadamente represivo. La dictadura de Hernández acabaría con la vida de entre 8.000 y 30.000 campesinos en la conocida represión del levantamiento campesino de Izalco en 1932 (Brockett 2005, p.130). En 1944, Hernández abandonaría el gobierno tras una de las mayores huelgas que se han llevado a cabo en América Latina. Sin embargo, esto no significó el comienzo de un proceso de democratización, por el contrario, cada intento de llevar a cabo algún tipo de reforma social o política fue aplacada por sucesivos golpes militares en 1944, 1960, 1972 y 1976. Cada uno de estos derrocamientos contó con el respaldo de las élites cafetaleras, quienes eran los que realmente dominaban el país, impidiendo el establecimiento de un gobierno estable y con capacidad de imponer el Estado de Derecho en el país.

Un caso diferente en América Latina es el de Chile. Entre 1973 y 1990, una junta militar liderada por el general Augusto Pinochet gobernó el país, después de derrocar a Salvador Allende y poner fin a casi medio siglo de democracia ininterrumpida. La dictadura de Pinochet suprimió los partidos políticos y cualquier otro tipo de actividad política, además reprimió duramente a todos aquellos "sospechosos" de participar en actividades insurgentes. Pero también fue capaz de controlar desde dentro cualquier tipo de oposición o amenaza. En 1974, el general Carlos Prats, ex-Comandante en Jefe del Ejército, quien había sido ministro de Allende y reconocido anti-golpista, fue asesinado en Buenos Aires junto a su esposa por mandato directo de la Junta Militar. También en 1977, Pinochet destituyó de la Junta al General de la Fuerza Aérea Gustavo Leigh, quien se había vuelto un importante crítico tanto del manejo político de Pinochet como de las reformas económicas impulsadas por los Chicago Boys (Valdivia 2003). De tal modo, a diferencia del caso salvadoreño, la dictadura militar chilena fue capaz de superar divisiones internas y mantener alineadas a las Fuerzas Armadas y con ello controlar completamente los medios de coerción. Además, aunque Pinochet perdió el plebiscito de 1988, su salida del poder fue dentro del marco institucional impuesto por la constitución redactada bajo su mando y que rige a Chile hasta hoy.

Los cuatro casos antes descritos corresponden a regímenes en que los niveles de democracia y de capacidad estatal, tal como han sido definido por el 
modelo del proceso político, presentan importantes variaciones y diferencias. Esta importante variación observada en regímenes autoritarios se contrapone a la situación que viven las estables democracias de Europa Occidental y Estados Unidos. Esto no es menor, considerando que la teoría de la acción colectiva contenciosa se ha nutrido principalmente del estudio de los movimientos sociales en estos contextos de estabilidad, lo que lleva a preguntarse hasta qué punto estos desarrollos teóricos pueden aplicarse en contextos no-democráticos (Osa 2003).

La literatura sobre autoritarismos se ha centrado en entender los aspectos institucionales de estos sistemas políticos y, en particular, sus procesos de quiebre y/o transición democrática. En esta literatura, el papel que se le ha otorgado a los movimientos de protesta en el quiebre de estos regímenes, ha estado supeditado a estos procesos de transformación institucional. En efecto, en los estudios de O’Donnell y Schmitter (1988), la referencia a las movilizaciones ocurridas en Latinoamérica y en el sur de Europa durante la "tercera ola" de democratización, son descritas como una "resurrección de la sociedad civil", la cual es explicada no tanto por la capacidad interna de los propios movimientos, como por la pérdida de control del régimen una vez iniciado el proceso de transición. Es más, estos autores sostienen que la mera existencia de una sociedad civil no es requisito ni para el declive de la autocracia ni menos para transitar a la democracia (Schmitter 1993). En esta línea, parece ser que los movimientos de protesta tendrían poco que ver con la desestabilización de los regímenes autoritarios y antes que una causa sólo serían un síntoma de la "debilidad institucional" en un momento determinado (McGlinchey 2009, p.125).

Así, este enfoque, aunque no ignora el rol de la movilización social, deja una importante brecha en la comprensión de aquellos casos de "resurrección de la sociedad civil" ocurridos previos a los procesos de democratización (Schock 2005, p. xviii). Por ejemplo, Oxhorn (1995) critica este enfoque en su estudio sobre la organización de la sociedad civil en Chile durante la dictadura de Pinochet, mostrando que este proceso de organización ocurrió varios años antes del inicio de la transición, y como consecuencia de la experiencia previa de organización de la población civil chilena. Un argumento similar es el que presenta Accornero $(2013 ; 2016)$ en sus trabajos sobre los movimientos de protesta iniciados después de la caída del dictador Salazar en Portugal en 1974. La autora muestra que lejos de la noción predominante que explicaba estas movilizaciones como consecuencia de la crisis política ocurrida luego del quiebre del régimen de Salazar, es necesario comprender las condiciones sociales preexistentes que podrían haber contribuido a la apertura de oportunidades políticas, además de la "mutua influencia entre la política institucional y los movimientos sociales, y no sólo los efectos unilaterales de la primera sobre los últimos" (Accornero, 2013 p. 1038).

Estos trabajos, junto a otros que se discuten en las siguientes secciones, muestran que la gran variabilidad de los contextos autoritarios no permite afirmar a priori si la protesta es causa o síntoma del quiebre de un régimen. Más bien, es necesario asumir las complejidades propias tanto de este tipo de regímenes, como de los movimientos de acción contenciosa y determinar qué variables explicar mejor el modo en que se desenvuelven las relaciones entre ambos fenómenos políticos y sus eventuales resultados.

\section{Protestas y Autoritarismos}

En los últimos años ha habido un creciente interés por el estudio de los movimientos de protesta y los regímenes autoritarios. Estos trabajos han coincidido en que la principal preocupación de los autoritarismos está relacionada con 
su supervivencia. Estos gobiernos deben enfrentar constantemente a amenazas o desafíos que pueden quebrarlos. Aquellos que son eficaces en la identificación de posibles desafíos internos y externos, y capaces de responder correctamente a ellos, son aquellos que logran permanecer en el poder (Hess 2013, p.21). Dos son las principales amenazas que deben enfrentar continuamente los gobiernos autócratas: horizontales y verticales. La primera amenaza, también denominada el problema del reparto del poder hace referencia a la existencia de élites que controlan recursos claves (dinero, armas, tecnología, etc) volviendo al régimen vulnerable frente a estos grupos. Por su parte, la amenaza de tipo vertical o el problema del control autoritario se refiere a aquellos desafíos planteados por la población hacia el régimen, principalmente -aunque no de modo exclusivo- a través de la acción colectiva contenciosa (Svolik 2012, también Schedler 2013).

Este último tipo de problema es el que se aborda en las siguientes secciones. Bajo un régimen autoritario altamente represivo, la construcción de organizaciones de base y la articulación de la acción colectiva contenciosa es un proceso difícil y dramático. Aun así, la protesta en contextos autoritarios no sólo es posible sino también es recurrente. Entonces ¿qué factores o circunstancias favorecen la acción colectiva contenciosa y que dinámicas específicas adquieren en contextos autoritarios? Hasta ahora los especialistas han continuado adoptando -y adaptando- el modelo del proceso político, dada la flexibilidad y dinamismo que ofrece para establecer relaciones entre la acción contenciosa y el régimen político, al mismo que lo han ido complementando con otros enfoques teóricos provenientes de diferentes áreas de investigación, como son los estudios sobre procesos democratizadores, y los estudios de seguridad y terrorismo, entre otros campos. Tres son las principales dimensiones que mayormente se han abordado en esta reciente literatura en lo que refiere a protestas y autoritarismos: Las oportunidades y amenazas políticas, los ciclos de contención y la sostenibilidad de los movimientos sociales, y la relación entre represión y protesta. Cada uno de estos aspectos pone énfasis en diferentes etapas de la política contenciosa: la emergencia del movimiento, la trayectoria que adquiere, y finalmente los posibles resultados en relación con los repertorios escogidos. La literatura muestra la ausencia de relaciones lineales o fácilmente predecibles entre cada uno de estos aspectos, por lo mismo estos trabajos ofrecen un panorama conceptual altamente desarrollado, y un abordaje analítico muy sofisticado que permite continuamente abrir nuevas preguntas y problemas sobre las diferentes experiencias de autoritarismos y política contenciosa.

\section{IV.1. Oportunidades y Amenazas Políticas en regímenes autoritarios}

En su estudio comparado de los regímenes autoritarios en Guatemala y El Salvador, Brockett (2005) acude al modelo del proceso político, e introduce una importante modificación conceptual a la definición de oportunidades políticas para explicar los sucesivos ciclos de protestas ocurridos en estos países. Esta modificación está basada en la crítica que hacen Goodwin y Jasper (apud Brockett 2005, p.15) sobre la utilidad de la noción de "estructura de oportunidades políticas", ya que esta conceptualización haría referencia a "factores relativamente estables en el tiempo y fuera del control de los movimientos", una característica que es poco habitual en contextos autoritarios. Por el contrario, Brockett (2005, p.15) sostiene que las oportunidades cambian rápida y significativamente, y que muchas de estas oportunidades pueden ser alteradas y promovidas por los propios movimientos sociales. En esta línea, Brockett (2005, p.16) prefiere utilizar la noción de "configuración de oportunidades políticas" haciendo referencia a la existencia tanto de elementos permanentes en el tiempo como aquellos que pueden ser manipulados por los actores políticos. 
Cada una de estas dimensiones de las oportunidades políticas variaría independientemente a través del tiempo, y con distintas consecuencias para la movilización en general. Por ejemplo, bajo una coyuntura específica es posible la apertura de una oportunidad de movilización para un grupo en mejor posición, el accionar de este grupo puede permitir la difusión de la protesta hacia otros grupos, robusteciendo el desafío colectivo al bajar los costos de participación para los demás actores. Las oportunidades políticas no corresponderían a factores estructurales que anteceden a la acción, sino que son actualizadas continuamente a través de la propia acción colectiva (Accornero 2016). De este modo, no basta con mirar "la forma en que los actores estatales definen el medio en el que actúan los individuos, sino también en la forma en que los grupos de protesta ayudan a modificar las condiciones en que actúan los individuos (Fillieule 2005, p. 214).

De modo similar, Almeida $(2003 ; 2008)$ recurre al modelo de oportunidades políticas en sus trabajos sobre los ciclos contenciosos en El Salvador durante el siglo XX. Almeida expande la comprensión del concepto de oportunidad política precisando que, mientras en democracias estas oportunidades sirven para aumentar las chances para la emergencia de un movimiento de protesta, en contextos no-democráticos las oportunidades corresponden a aquellos elementos que facilitan, en primer lugar, la formación de organizaciones autónomas de la sociedad civil. En esta línea, Almeida identifica dos tipos de oportunidades políticas para el caso salvadoreño: el acceso institucional y las elecciones competitivas. El primer tipo hace referencia a nuevas leyes, agencias de estados y "gestos simbólicos emitidos por el estado hacia la sociedad civil actuando como fuerzas positivas para los grupos desempoderados" (Almeida 2003, p.349). Hacia 1960, la dictadura salvadoreña implementó reformas políticas que se tradujeron, entre otros aspectos, en la expansión de la educación pública junto a la legalización de las organizaciones de profesores, y el apoyo a la creación de cooperativas en asociación con la Iglesia Católica (Almeida 2003, p.357-ss). Esta apertura institucional dio paso a la formación a una importante infraestructura organizacional, encabezada por maestros, trabajadores urbanos y estudiantes, quienes liderarían las olas de protesta en dicho país. Respecto de las elecciones competitivas, después de 32 años de existencia de un solo partido militar, en 1963 el régimen modificó el sistema electoral como consecuencia de la presión ejercida por el Partido Demócrata Cristiano. Esta modificación no sólo abriría la puerta a la participación de nuevas fuerzas política, sino que además rápidamente el régimen vería mermado su poder en el parlamento (Almeida 2003, p.360-ss).

Otra importante contribución de los trabajos de Almeida es el uso de la noción de "amenaza política". Esta refiere a la "probabilidad de que los beneficios existentes sean arrebatados o que sean infligidos nuevos daños si los grupos fallan al actuar colectivamente" (Almeida 2003, p.347). Al introducir este concepto, Almeida afirma que la protesta en regímenes autoritarios no sólo es facilitada por la apertura de oportunidades, sino también puede ser "inducida" por una amenaza política. Este autor identifica que las principales amenazas que indujeron la movilización de la sociedad civil salvadoreña fueron el drástico aumento de la represión y violencia del Estado a partir de 1975, la erosión de los derechos alcanzados, y los problemas económicos atribuidos al Estado. Además, Almeida observa una importante diferencia entre aquella movilización facilitada por la expansión de las oportunidades, y aquella inducida por las amenazas políticas. Mientras en la primera, la movilización tiende a ser más moderada en sus tácticas y repertorios; en la segunda, en respuesta del incremento continuo de la represión y del ambiente general de amenaza por parte del régimen, aquellos grupos cívicos bien organizados y con recursos, 
radicalizan sus estructuras y estrategias de acción, volviéndose progresivamente violentos (Almeida 2003; 2008).

Las "amenazas políticas" como concepto para explicar la "inducción" de la acción política contenciosa se encuentra menos desarrollado en la literatura en comparación con el de las "oportunidades políticas". No obstante, tal como muestra Almeida, las "amenazas" a posiciones y recursos obtenidos a través de la movilización, pueden inducir no sólo a continuar movilizándose sino a radicalizar la protesta. Es común que, en regímenes autoritarios, las personas se encuentren en una posición de amenaza, antes que en un contexto de oportunidades favorables para la acción colectiva. De hecho, Jenkins et al. (2003, p.282) sostienen que los grupos son más sensibles a las "amenazas", ya que al sobrevalorar los recursos propios habría una sobrestimación del impacto negativo de las pérdidas de tales recursos pudiendo "responder más rápidamente a las amenazas usando redes y prácticas existentes, mientras que, por otra parte, las respuestas a las oportunidades políticas demandan mucho tiempo y una movilización costosa".

Los individuos que viven en contextos autoritarios se encuentran en una posición crónica de subyugación frente al gobierno, sin embargo éstos puede movilizarse cuando ciertos arreglos alcanzados dentro de tal condicion son amenazados por cambios profundos dentro del régimen. Esto puede ocurrir por la llegada de nuevas élites que modifican su relación con la sociedad civil y, en lugar de abrirse un espacio de oportunidades políticas, se generan condiciones amenazantes para estos grupos, como ocurrió en El Salvador que bien caracteriza el trabajo de Almeida. Las amenazas tambien pueden surgir porque el régimen político es modificado en su totalidad, como cuando se pasa desde, por ejemplo, una democracia a una dictadura por medio de un golpe de Estado, como es el caso chileno en 1973 hasta 1989. De igual modo, es posible que, por diferentes razones, el régimen cambie la intensidad y dirección de sus actividades represivas, a tal punto que dichas actividades alcancen a sectores que hasta ese momento no habían sido víctimas de la represión, y entonces -como se verá en la sección sobre violencia represiva- estos grupos reaccionen colectivamente para oponerse al régimen. En este sentido, son las amenazas políticas, probablemente más que las oportunidades, las que mueven a los sujetos en régimenes autoritarios a embarcarse en acciones colectivas altamente costosas para su integridad.

IV.2. Ciclos de Protesta: entre la sostenibilidad de la acción colectiva y la dominación estatal

Los estudiosos de la protesta en regímenes autoritarios han coincidido en tomar los "ciclos de protesta" como la unidad de análisis privilegiada. Esto es así porque esta unidad presenta una serie de importantes ventajas analíticas y empíricas para este tipo de investigaciones. En primer lugar, adoptar un enfoque centrado en los "ciclos de protestas" se justifica en el hecho de que esta es la principal forma que adquieren los desafíos populares en estos regímenes. Dado que involucrarse en actividades de protestas conlleva un alto riesgo, y ya que los individuos carecen de acceso rutinario a las instituciones o de algún tipo de capital para influir en la política, su principal recurso reside en "sus números", es decir, en la capacidad que tengan los disidentes de atraer la mayor cantidad de grupos, organizaciones e individuos para oponerse pública y contenciosamente al régimen, a pesar de los riesgos que ello implica (DeNardo 1985). Los "ciclos de protestas" corresponden a fases de aumento del conflicto y la contención por todo el sistema social, y a una rápida difusión de la acción colectiva desde los sectores más movilizados a los menos movilizados (Tarrow 1993, pp.284-285). En palabras de Mark Beissinger, los "ciclos de protesta" corresponden a periodos de "espesor histórico" (thickened history), donde "el ritmo de los 
eventos desafiantes [al régimen] se acelera hasta el punto de que es imposible comprenderlos y llegan a constituir una parte cada vez más significativa de su propia estructura causal" (Beissinger 2002, p. 27).

Asimismo, los "ciclos de protesta" no sólo se refieren al aumento abrupto de la actividad contenciosa, sino también a la dimensión temporal dentro de la cual la protesta se desenvuelve y evoluciona. Los eventos de protestas no corresponden a acontecimientos aislados e intercambiables entre sí, como si estuvieran aleatoriamente distribuidos en el tiempo y el espacio. Por el contrario, la característica distintiva de la acción colectiva es su "conectividad, histórica y espacial, y ambas con otras instancias de acción colectiva del mismo tipo, y con las acciones de diferentes reivindicadores, tales como las autoridades o contra-movimientos" (Koopmans 2004, p.19). Además, poner atención en los ciclos de protestas, permite ir más allá del mero análisis de un movimiento $\mathrm{u}$ organización en particular, y considerar las interacciones que se dan entre todos los contendientes, no únicamente los opositores, sino también sus aliados, terceras partes y el propio régimen. Asimismo, permite examinar la totalidad de las acciones y estrategias de que van desplegando los desafiantes, desde aquellas de baja intensidad hasta las más disruptivas e incluso violentas (Koopmans 2004, p.21). Siguiendo la propuesta interaccionista de Jasper (2015), podría decirse que los ciclos de protesta, al poner su atención en todos los "jugadores y arenas" en disputa, y no sólo en un movimiento en un momento específico, permiten visibilizar el "tiempo, la interacción, y los procesos, todos los cuales son oscurecidos en la mayoría de los modelos estructurales" (Jasper 2015, p.22).

En suma, un ciclo de protestas corresponde a un periodo donde la "conectividad" de la acción colectiva es particularmente densa y consecuencial, tanto en las relaciones e interacciones entre los contendores, como en la secuencia en la que se despliegan estas interacciones. Como bien señala Oliver (1989, p.2), "las acciones pueden afectar la probabilidad de que se produzcan otras acciones creando ocasiones para las mismas, alterando las condiciones materiales, cambiando la organización de un grupo, modificando las creencias o aportando nuevos conocimientos". No obstante, a esto habría que agregar la dimensión temporal de la contienda: una misma acción puede tener diferentes probabilidades y resultados dependiendo de la fase del ciclo en la cual se lleva a cabo. Una mala elección estratégica por parte de los primeros desafiantes al inicio de un ciclo puede significar una rápida derrota del movimiento. De igual modo, un régimen que decide reprimir violentamente durante el "peak" contencioso del ciclo, puede obtener un resultado no deseado. Así, aunque los comienzos de los ciclos sean en similares entre sí, la trayectoria, el modo en que concluye y sus consecuencias posteriores, son mucho más dispares (Tarrow 2013).

Sin duda, los ciclos de protesta corresponden probablemente al único medio que tiene la sociedad civil de plantar un desafío importante a un autoritarismo. Las movilizaciones populares que han logrado la caída de gobiernos autoritarios se han caracterizado por alcanzar una sucesión de ciclos de protestas en periodos determinados de tiempo, por lo general cada uno de estos ciclos con mayor número de opositores y mayores niveles de contención (Kricheli et al., 2011). No obstante, los estudiosos también han mostrado que montar ciclos de protestas no garantiza el éxito en la consecución del quiebre del régimen (Hess 2013, Goodwin 2001). Lo que podría denominarse como la "sostenibilidad" de la acción colectiva, es decir, la capacidad de aumentar las chances de éxito a medida que los ciclos de protestas convocan a más gente y aumentan sistemáticamente el grado de contención durante las acciones colectivas (sin que esto implique necesariamente campañas violentas), sólo es posible en la medida en que los grupos que participan de estos ciclos logren establecer y mantener relaciones entre ellos incluso después de haber declinado la campaña en 
específico. Es lo que Staggenborg (1998) ha definido como la formación de "comunidades del movimiento social", las cuales abarcan a "todos los actores que comparten y promueven los objetivos de un movimiento social: las organizaciones del movimiento (SMO); partidarios de movimientos individuales que no necesariamente pertenecen a las SMO; partidarios del movimiento institucionalizados; instituciones alternativas; y grupos culturales" (Staggenborg 1998, p.182). Lo fundamental de las comunidades del movimiento social tiene que ver con el grado de cohesión, así como la extensión de los lazos que los grupos que forman las comunidades durante un ciclo de protesta, ya que esto incide directamente en la sostenibilidad de la acción colectiva, especialmente en contextos autoritarios. Para Staggenborg (1998, p.186) son los lazos fuertes los que permiten construir redes más densas y evitar faccionalismo, además de proporcionar alianzas más duraderas y liderazgos estables a través de diferentes grupos. Con ello se facilitaría la activación de nuevos ciclos de protestas, cuyos participantes se encuentran cada vez más cohesionados, dando paso a la emergencia de nuevos repertorios y marcos de acción colectiva. Lo anterior haría más dificíl al gobierno poder controlar y anticipar las actividades opositoras de la sociedad civil, provocando una progresiva desestabilización del régimen.

Ahora bien, la configuración de las relaciones y la fuerza que adquieran las comunidades de un movimiento social no dependen únicamente de la voluntad del propio movimiento. La trayectoria de los ciclos de protestas está profundamente trazada por las características del Estado. Ya se ha visto la amplia variación existente tanto en los niveles de democracia como de capacidad que pueden mostrar los autoritarismos, de ahí que también se observe amplia variabilidad en los tipos de movimientos de protestas, sus respectivas trayectorias, y resultados. En esta línea, Boudreau (2005) pone atención en la relación entre la estructura y operación de poder de los grupos opositores, y la estructura y operación de la dominación del Estado a fin de examinar qué tipo de dinámicas contenciosas se desarrollarán en un momento determinado. Para este autor, son dos los elementos que deben considerarse al respecto: la amplitud y la profundidad del poder de los oponentes, y del Estado. Con estos elementos a la vista, Boudreau se pregunta, por ejemplo, si el Estado controla ciertos enclaves de la sociedad o ha logrado penetrar en áreas geográficas de difícil acceso; o si los movimientos están constituidos únicamente por redes locales o por vínculos a nivel nacional. De esta manera, los Estados y movimientos sociales pueden cada uno ser de amplio o corto alcance, superficiales o profundos, y la confrontación entre ellos puede ir desde episodios inocuos, donde movimientos sociales de corto alcance y superficiales confronten a un régimen amplio y enraizado en la población; hasta aquellos enfrentamientos fundamentalmente desestabilizadores donde, por ejemplo, un movimiento social profundo y amplio desafíe a autoridades con superflua influencia (Boudreau 2005, p.39).

Similar a lo formulado por Boudreau, se encuentra el trabajo de Hess (2013), quien pone especial atención en cómo los regímenes autoritarios distribuyen autoridad y recursos entre el centro y las unidades territoriales subnacionales (Hess 2013, p.33). Este autor sostiene que a medida que los regímenes transfieran poder hacia los gobiernos locales, éstos serán mucho más efectivos en la capacidad de respuesta general del gobierno, y al mismo tiempo, impedir demandas populares por democratización (Hess 2013, p.34). Esto es así, ya que "cuando las autoridades subnacionales poseen una parte significativa de los recursos del Estado y de la autoridad en la toma de decisiones, los líderes de las protestas locales perciben que sus agravios particulares pueden ser efectivamente conducidos, llevando a cabo acciones colectivas limitadas a la comunidad en específico". Este hecho impediría la formación de comunidades de movimiento social de alcance nacional, reduciendo la acción contenciosa a una de tipo local y con demandas limitadas, y en la que las autoridades locales 
poseen los suficientes recursos o bien para negociar o bien para reprimir. Entre los casos de autoritarismos que incluye en su estudio se encuentran China y Taiwán, países que desarrollaron un régimen de partido único pero cuyas trayectorias en torno a la centralización del poder estatal se diferenciaron de forma importante. China, que optó por una estructura descentralizada de la autoridad estatal, se caracterizó por presenciar ciclos de protestas descoordinados, fragmentados y localizados, incapaces de avanzar hacia una movilización sostenida de alcance nacional, y fácilmente contenidas por las autoridades locales. La única excepción serían las movilizaciones nacionales en torno a la masacre de la plaza de Tiananmén en 1989. Por su parte, Taiwán desarrolló una estructura de poder completamente centralizada, como consecuencia de lo anterior las movilizaciones rápidamente se expandieron, alcanzando tal poder que obligaron al Partido Nacionalista a realizar profundas reformas políticas, entre ellas el permitir competición multipartidista.

Hess (2013) pone el foco en la distribución de poder dentro del Estado para determinar la capacidad de resiliencia de un régimen autoritario frente a desafíos populares. La centralidad del poder del Estado parte de la observación hecha por Tilly (1994) en la que señala que en la medida en que lo Estado nacional se expandió y penetró en la sociedad, sin quererlo también centralizó los objetivos de la movilización colectiva sobre sí misma, que antes estaban dirigida hacia los señores u otras autoridades locales. Así, la aparición del Estado nacional inevitablemente daría paso a movilizaciones de tipo nacional. Hess también muestra que la mera existencia de ciclos de protestas no tiene como resultado el quiebre del régimen, ni siquiera su desestabilización. Tal como se ha señalado anteriormente, los ciclos de protestas son el único modo de desafiar a un régimen autoritario que tiene la sociedad civil, pero para que ello sea así deben hacer que la acción colectiva sea sostenible en el tiempo, y permita la creación de comunidades de movimientos sociales con lazos fuertes y extensos que faciliten la rápida difusión de la protesta, y la creación de nuevos y disruptores repertorios de contención. Ciclos de protestas que no sean más que la agregación de protestas descentralizadas, fragmentadas o sin coordinación harán mucho más fácil el trabajo al Estado en su desactivación, aumentando rápidamente los costos que para los opositores embarcarse en acciones colectivas contenciosas.

Independiente del tipo de desafío colectivo que articulen los grupos opositores -fuerte, débil, amplio, localizado, etc.- los autócratas igualmente se ven obligados a movilizar recursos con el fin de evitar un escalamiento mayor. Schock (2005) clasifica en cuatro las posibles opciones que tienen los gobiernos para responder a un desafío colectivo: ignorar, conciliar, reformar o reprimir. Ahora bien, ignorar un desafío popular no es posible en autoritarismos ya que, a diferencia de las democracias bien establecidas, siempre estos desafíos son contenciosos, es decir amenazan directamente la sobrevivencia del régimen. $\mathrm{La}$ conciliación, por otra parte, corresponde a "gestos simbólicos" que pretenden un acercamiento hacia los grupos opositores a través de la cooptación a fin de moderar las demandas, así como las formas de acción colectiva más disruptivas. En cambio, las reformas son concesiones concretas hacia los grupos agraviados, los cuales bajo gobiernos autoritarios pueden provocar un "efecto de arrastre", es decir un aumento de grupos opositores demandando reformas más y más radicales poniendo en serio peligro al régimen (Shock 2005, pp.30-31). Finalmente, la represión constituye el modo característico de la relación que establecen los autoritarismos hacia los grupos opositores. La represión se refiere a la restricción forzada de las libertades civiles y políticas por diferentes medios. Frente a los movimientos de protestas en regímenes autoritarios, la represión adquiere principalmente la forma de violencia directa aplicada sobre los manifestantes. El impacto, tanto para los grupos desafiadores como para el régimen 
mismo, de la relación violencia represiva-protesta son múltiples y muy variados dependiendo del contexto histórico y político en el que está inserto el conflicto. En la siguiente sección se discuten algunos elementos que caracterizan esta relación en los autoritarismos.

\section{Violencia política en autoritarismos: represión estatal y tipos de resistencia}

El asunto de la violencia represiva en los regímenes autoritarios y su relación con la protesta es, tal vez, el tema más abordado en la literatura. Esto es así dado que es la forma más visible y concreta del conflicto entre los autócratas y la población civil. Al mismo tiempo, es la más compleja de analizar, dado los múltiples elementos que contiene y preceden a esta relación, así como sus inciertas consecuencias. Desde la perspectiva del régimen, la sobrevivencia es la principal prioridad, por lo tanto, frente a posibles amenazas de tipo vertical lo óptimo es adelantarse a ellas y desarticularlas. No obstante, dado que esto no siempre es posible y las acciones colectivas contenciosas se activan inevitablemente, el uso de la violencia como medio de represión pone al régimen ante lo que algunos especialistas han llamado el "Dilema del Dictador". Es decir, cuánta violencia represiva es necesaria para desalentar la protesta sin que esto provoque una reacción contraria de radicalización y escalamiento en la oposición de la sociedad civil (Francisco 2006, p.59). Este dilema describe una función curvilínea en la relación entre represión y protesta. Esta relación conocida como la "hipótesis de la reacción" asume que, aunque en niveles altos de coerción la protesta decaerá temporalmente, en el largo plazo los grupos disidentes aumentarán sus actividades de protesta y oposición contenciosa especialmente cuando la represión es aplicada de modo indiscriminado (Mason \& Krane 1989).

Es esta forma curvilínea en la relación represión-protesta, la que parece ser el modo dominante en ciertos regímenes autoritarios. Por ejemplo, Francisco (2005) analizó diez episodios de alta represión violenta en autoritarismos y, con la sola excepción de China, en cada uno de ellos la respuesta fue el aumento de los niveles de protesta con objetivos radicales, ya sea en campañas no-violentas como la de Gandhi en India o la lucha contra del Apartheid en Sudáfrica; o derechamente violentas como fue el surgimiento del Ejercito Republicano Irlandés (IRA) que abogaba por la independencia de su país frente al Reino Unido (Francisco 2005, pp.61-63). El razonamiento que parece estar detrás de estos episodios es que el aumento continuo e indiscriminado de la violenciarepresiva por parte del Estado, en el largo plazo terminará por disminuir los costos adicionales de protestar (Menke, White \& Carey 2002, p.5). Una idea similar sostiene Jeff Goodwin en su estudio sobre movimientos revolucionarios durante el siglo XX. Goodwin (2001), quien también se basa en las observaciones de Mason y Krane (1989), sostiene que es la violencia indiscriminada por parte del Estado lo que provocaría una reacción contraria a la esperada, produciendo un aumento progresivo e irreversible de movilización de grupos revolucionarios (Mason \& Krane 1989, p.48). Para este autor, las personas que se involucran en este tipo de grupos y actividades lo hacen como último recurso para lograr modificar su extrema situación de agravio, no sólo económico sino también cultural y político, y luego de haber sido reprimidos violentamente cada vez que recurrieron a otras estrategias de presión. En otras palabras, "las personas a veces concluyen que la revolución en su única salida" (Trostky apud Goodwin 2001, p.26).

Ahora bien, no todos los autoritarismos requieren aplicar del mismo modo la violencia represiva sobre los grupos opositores y sus actividades de protesta. Como se ha visto hasta acá, existen diversos tipos de autoritarismos, cada uno de los cuales ofrece un contexto político determinado para la emergencia de 
diferentes movimientos de protesta, y un modo específico para lidiar con dichos movimientos. Siguiendo a Levitsky y Way (2010), aquellos autoritarismos competitivos, donde el Estado y las estructuras del partido gobernante están bien organizadas y bien cohesionadas, las actividades de los opositores son permitidas formalmente, dificultando la organización de movimientos radicalizados y sostenidos, permitiendo al régimen ser más selectivo en el uso de la violencia. De igual modo, el ya mencionado estudio de Hess (2013) muestra que aquellos autoritarismos capaces de descentralizar su capacidad coercitiva son más eficientes en desactivar movimientos de protestas a nivel local, ya sea a través de concesiones específicas o el uso limitado y focalizado de la represión. Ambos estudios muestran cómo la estabilidad que un autoritarismo logra a través de arreglos institucionales específicos puede contribuir a evitar usar la violencia represiva y con ello disminuir las probabilidades de emergencia de un movimiento de oposición radical y poderoso.

De igual modo, existen autoritarismos que no gozan de los mismos niveles de estabilidad institucional ni de capacidad coercitiva y, por lo tanto, el uso que hacen de la represión adquiere una relación diferente frente a los movimientos de protesta. Estos regímenes, aunque autoritarios, no pueden mantener los niveles de violencia extrema de forma permanente y, al contrario, presentan una amplia variación en su comportamiento represivo: desde periodos de baja represión a momentos de violencia indiscriminada. Bajo este tipo de regímenes es posible encontrar una relación entre represión y protesta que adquiere la forma una "U” invertida. En este caso, el razonamiento detrás de esta relación es que en aquellos regímenes no-represivos, los grupos civiles de oposición pueden usar otros canales disponibles para alcanzar sus objetivos; mientras que en regímenes totalmente represivos los costos y riesgos asociados a protestar son demasiados altos, manteniendo a los oponentes del régimen fuera de las calles. No obstante, en regímenes "semi-represivos" los grupos de oposición pueden ser movilizados y ningún otro medio además de la protesta es factible para manifestar el descontento y oponerse al gobierno (Muller \& Weede 1990).

En relación con lo anterior, Brockett (2005) ha desarrollado un argumento similar para explicar lo que denomina como la "paradoja Protesta-Represión" en Guatemala y El Salvador, regímenes que si bien considera autoritarios los califica como "semi-represivos". Para este autor, la relación existente entre protesta y represión no sólo se explica por el nivel de los agravios o el comportamiento represivo del régimen, sino que esta relación está condicionada por el "nivel general de movilización popular preexistente en el punto en el cual la represión inicia o se incrementa. Es decir, la clave para resolver la paradoja protesta-represión es la variable temporal interviniente de la ubicación en el ciclo de protesta" (Brockett 2005, p.269). Este argumento presenta una explicación más dinámica dentro de la relación entre protesta y represión, al integrar un elemento contingente y temporal, como es la fuerza de un ciclo de protesta y el momento en el cual el régimen decide reprimir. Así, cuando el nivel de represión sobrepasa en fuerza a la oposición popular entonces los niveles de protesta tenderán a disminuir. Del mismo modo, el nivel de violencia represiva necesaria para ofuscar un movimiento de protesta será menor cuando los niveles de movilización están en su mínimo; no obstante, la violencia represiva deberá aumentar si es que el régimen espera reprimir un ciclo de protestas que se encuentra en su nivel más alto (Brockett 2005, pp.269-270). Así, si el régimen no cuenta con la capacidad para reprimir en el momento preciso un ciclo en avanzada, entonces su supervivencia se verá seriamente amenazada. Contrariamente a la "hipótesis de la reacción" que plantea que luego de cierto umbral de represión los costos de protestar no aumentan y las personas tenderán a ver como su "única salida" unirse a movimientos revolucionarios, Brockett (2005, p.271) sostiene que el aumento de los agravios no lleva directamente a un 
aumento en la actividad política, sino más bien "el ritmo y la intensidad de la emergencia de un movimiento estará relacionado con los niveles previos de contención logrados en el pasado, por una parte, y la ferocidad y duración de la represión recientemente experimentada, por otra parte".

El dinamismo que pone Brockett (2005) al integrar el desarrollo del ciclo de protesta como variable mediadora en el análisis de la relación entre protesta y represión, queda hasta cierto punto limitado por el modo en el que aborda las actividades contenciosas examinadas. En efecto, el autor considera que al hacer una distinción entre formas de protestas violentas (como la guerrilla) y aquellas no-violenta (como marchas, boicots, huelgas, etc.) simplifica el hecho de que los mismos individuos pueden participar paralelamente en ambos tipos de protestas (pp.13-14). El problema con este razonamiento está en que, si bien una persona puede participar en ambos tipos de protestas, la militancia en una organización de lucha no-violenta y de aquella que decide usar la violencia nunca es totalmente paralela. No todas las personas participan en ambos tipos de actividades a la vez, por lo cual las consecuencias analíticas, pero también para el desarrollo del conflicto político pueden ser totalmente disímiles. Como bien ha señalado Schock $(2005$, p.6) aunque los conflictos contenciosos en regímenes no-democráticos frecuentemente involucran acciones violentas y no-violentas, es "necesario realizar distinciones conceptuales entre ambos tipos de resistencia para entender más claramente el rol de las estrategias y tácticas en las dinámicas de la contención”.

El propio Schock (2005) ha sido uno de los más críticos en esta línea. Este autor ha señalado que ha habido un importante mal entendimiento entre los cientistas sociales respecto de lo que implica las acciones colectivas contenciosas no-violentas en regímenes autoritarios. Es posible que esto se deba al hecho de que los métodos no-violentos suelen asociarse más al tipo de política contenciosa que se encuentra en países con democracias desarrolladas. Esto ha llevado, siguiendo a Schock, a que los especialistas consideren erróneamente las acciones no-violentas como "resistencia pasiva"; como el último recurso utilizado cuando los medios de violencia no están disponibles; o que es un método de las clases medias limitado sólo a perseguir objetivos moderados o reformistas; y que los resultados de estas acciones no-violentas están determinadas únicamente por la capacidad y/o propensión del régimen a reprimir violentamente (Shock 2005, pp.6-11). No obstante, junto con el trabajo de Schock ya citado, existe amplia evidencia que muestra que los métodos no-violentos no sólo abundan en regímenes no democráticos, sino que son el doble de exitosos en acabar con autoritarismos que los métodos más violentos (Chenoweth \& Stephan 2011, p.9). Por ejemplo, Nepstad (2011) encontró de que de los 67 autoritarismos que fueron desmantelados entre 1972 y 2002, cerca del $70 \%$ fueron resultado de la emergencia de campañas no-violentas. También Stephan y Chenoweth (2008) analizaron campañas violentas y no-violentas entre 1900 y 2006 en diferentes tipos de régimen, y encontraron que un 53\% de las campañas no-violentas fueron exitosas, comparadas con un $23 \%$ para aquellas violentas (p.8). Estos mismos trabajos han enfatizado las ventajas que presentan este tipo de acciones, por ejemplo: amplían la participación y permiten aumentar las alianzas (Chenoweth \& Stephan 2011); aumentan la presión internacional sobre el régimen (Schock 2005); y, eventualmente, pueden provocar deserciones o divisiones dentro de la élite gobernante, debilitando el poder del Estado (Nepstad 2011) con posibles consecuencias nefastas para el propio régimen. Básicamente, el poder levantar una campaña contenciosa no-violenta permite la configuración de nuevas oportunidades políticas para los oponentes.

Estos trabajos muestran que es fundamental diferenciar conceptualmente entre actividades violentas y no-violentas, ya que en contextos autoritarios y, sobre todo, en momentos de alta conflictividad, ambos tipos de resistencia se 
presentan en forma simultánea con importantes implicancias en lo que respecta a las posibles respuestas del Estado y a los eventuales resultados de estas acciones para los grupos que las llevan a cabo. Por ejemplo, en su completo estudio sobre la resistencia civil no-violenta durante el siglo XX, Chenoweth $\mathrm{y}$ Stephan (2011) argumentaron que el grado de éxito que tienen este tipo de campañas contenciosas está directamente relacionado con el hecho de que las barreras de participación en estas actividades son muchísimo menores que aquellas más violentas. Así, tal como se observó en la sección anterior, la densificación participativa que es facilitada por las campañas no-violentas, contribuiría a "un número de mecanismos necesarios para el éxito, incluyendo una mejor capacidad de recuperación, mayor probabilidad de innovación táctica, disrupción cívica expandida (por medio de la elevación de los costos para el régimen de mantener el statu quo) y cambios de lealtad de oponentes a partidarios" (Chenoweth y Stephan 2011, p.25). En otras palabras, las campañas no-violentas aumentarían la sostenibilidad del movimiento social, así como su capacidad de configurar nuevas oportunidades políticas.

De igual modo, en un reciente artículo Chenoweth y Schock (2015) se preguntaron si la existencia de movimientos armados afecta los resultados de las campañas contenciosas no-violentas. Sus hallazgos mostraron efectos tanto positivos como negativos respecto de los objetivos perseguidos, y en el largo plazo las campañas no-violentas fueron exitosas a pesar de la presencia o ausencia de movimientos armados. Estudios anteriores, no obstante, encontraron cierta evidencia de que la presencia de grupos de oposición que han optado por la lucha armada tiene un efecto negativo sobre las actividades de los grupos no-violentista. Las hipótesis detrás de estos estudios son que la presencia de un grupo opositor especialista en violencia podría a) inducir al régimen a extender sus acciones represivas contra todos los oponentes b) reducir los niveles de participación popular, y c) la alienación de potenciales partidarios externos (Chenoweth \& Stephan 2011; Pearlman 2011).

A pesar de la gran variabilidad de resultados, la complejidad analítica y los problemas planteados, estos trabajos son particularmente valiosos y pertinentes para el estudio de las acciones colectivas de oposición en las experiencias autoritarias de América Latina del siglo pasado. Por ejemplo, a finales de década de 1960 e inicios de 1970, en México emergieron una serie de guerrillas urbanas, la más famosa fue la "Liga 23 de Septiembre", la cual entre otros hechos de violencia, se le reconoce por el asesinato del candidato presidencial del PRI, Eugenio Garza Sada. El régimen llevo una dura "guerra sucia" en contra de estos grupos, pero su represión también se extendió a movimientos de oposición no-violentos como los estudiantes, quienes sufrieron doblemente la violencia del partido: en 1968 en la masacre de Tlatelolco y luego en 1971 en la masacre de Corpus Christi. También vale la pena mencionar el caso chileno bajo la dictadura de Pinochet. Durante este periodo y especialmente en la década de 1980 convivieron grupos violentistas como el Movimiento Revolucionario de Izquierda o Frente Patriótico Manuel Rodríguez, junto con movimientos de oposición no-violentos como la Alianza Democrática. Acá también parece ser que el régimen extendió la represión sobre todos sus oponentes, pero la existencia de grupos armados no provocó la reducción de la participación popular, ni la alienación de potenciales aliados externos. Por el contrario, la fuerte presencia de la Iglesia Católica y de ONGs y otros grupos de presión internacionales fortalecieron amplia y continuamente la opción no-violenta de lucha. En cualquier caso, no es posible afirmar con toda certeza que fue gracias a la oposición popular no-violenta que la dictadura chilena terminara a fines de la década de 1980.

Por su parte, en cuanto a las consecuencias que tiene para el régimen enfrentar campañas violentas y no-violentas, ya se ha visto que el segundo tipo 
parecen ser nefastas para la supervivencia del dictador. Es claro que, en términos de fuerza, en la medida en que el régimen tenga control sobre las armas será más fácil enfrentar desafíos violentos. Sin embargo, aquellas campañas no-violentas logran erosionar rápida e irreversiblemente la legitimidad del régimen, en especial si éste responde con violencia, pudiendo inducir un efecto de reacción en la población civil aumentando la participación, radicalización y facilitando el apoyo de aliados externos (Chenoweth \& Stephan 2011). Por eso el Estado debe elegir cuidadosamente su estrategia de respuesta frente a este tipo de acciones colectivas, es decir debe actuar lo más racional posible a fin de superar exitosamente este "Dilema del Dictador". Boudreau (2005) sostiene que en autoritarismos sin hegemonía y, por tanto, donde continuamente deben enfrentar desafíos colectivos populares, no suelen contar con los recursos suficientes para ejercer su poder sobre la totalidad del territorio ni sobre todos los aspectos de la vida social, y por tanto requieren realizar un "trade-off" entre los esfuerzos destinados a fortalecer la institucionalidad del régimen y los recursos necesarios para enfrentar campañas contenciosas. De esta manera, aunque se esperaría que mientras más fuerte sea un movimiento de protesta más probable que el régimen recurra a la violencia, lo cierto es que las estrategias e intensidad de las respuestas por parte de los gobernantes "dependerá de las lecturas más profundas [que haga el régimen sobre] las amenazas que plantea un desafío social particularmente estructurado a instituciones particularmente estructuradas del Estado" (Boudreau 2005, p.54). Esto lleva a que en la aplicación de violencia represiva sobre movimientos de oposición no-violentos, el régimen busque legitimar sus acciones presentando a estos desafíos como verdaderas amenazas al orden público o a la estabilidad política (p.34).

\section{VI. ¿Qué se sabe sobre la política de la protesta en regímenes autoritarios? Consideraciones finales}

En primer lugar, la evidencia ha mostrado que a pesar de los elevadísimos costos que tiene levantar movimientos de protesta en regímenes autocráticos, éstos no sólo son posibles sino bastantes recurrentes. Esto lleva a problematizar la idea que exista una "estructura de oportunidades políticas" y sea más pertinente hablar de "configuraciones de oportunidades políticas". Esto es así porque como bien notó Brockett (2005) la noción de "estructura" parece relacionarse con aspectos permanentes del Estado a los cuales los oponentes pueden, cada cierto tiempo, acceder para levantar acciones contenciosas. No obstante, precisamente porque los autoritarismos son regímenes donde no existe verdadera competencia y flexibilidad política, es que éstos están continuamente expuestos a momentos de desestabilización y amenaza. Estos momentos permitirían la configuración de oportunidades políticas, entendiendo este concepto como una serie de procesos históricos y contingentes en el cual diferentes actores, populares y estatales, se enfrentan para definir y redefinir las relaciones de poder dentro del régimen. Esta noción no sólo pone énfasis en los aspectos estructurales o históricos, sino también en aquellos contingentes en los cuales los movimientos de oposición pueden contribuir ellos mismos a la difusión de la protesta contenciosa, abriendo oportunidades de movilización para para otros grupos desafiantes.

Ahora bien, la activación y difusión de la protesta contenciosa es sólo el inicio del conflicto político entre el régimen y la población civil. En su desarrollo, así como en su conclusión ingresan otros elementos que deben considerarse para determinar posibles trayectorias y outcomes. Desde el punto de vista del movimiento social, parece haber consenso entre los especialistas en que el mayor poder al que pueden acceder los grupos contestatarios radica en sus "números", es decir en la capacidad de reclutamiento y retención que logren los líderes del desafío colectivo, pero también su capacidad para mantener la movilización en el largo plazo, y de progresivamente ir disminuyendo los 
costos de volver activar la protesta. Al respecto, en este trabajo se ha utilizado la noción de "sostenibilidad" de la acción colectiva contenciosa. Este concepto ha sido utilizado principalmente en el área de la ecología para referirse a una serie de procesos biológicos (a toda escala) en que las especies buscan mantenerse equilibradamente en el tiempo adaptándose a su entorno y a los cambios que éste puede experimentar en la historia. Así, un movimiento social "sostenible" entonces sería aquel no sólo capaz de mantenerse denso numéricamente en el entorno hostil que significa un régimen autoritario, sino también capaz de ir adaptándose continuamente en el tiempo a través de la innovación continua de nuevas tácticas y estrategias de lucha contenciosa.

Por su parte, los regímenes autoritarios también luchan por su sobrevivencia en el poder. Por tanto, están obligados a responder a los desafíos impuestos por la población civil agraviada. Los trabajos acá expuestos y discutidos coinciden en la presencia permanente de la violencia como el árbitro final de la política en los autoritarismos (Svolik 2010). Asimismo, también coincidieron en que el uso de la violencia represiva y su relación con los movimientos de protesta no era ni lineal ni predecible. Por ejemplo, para explicar la emergencia de movimientos revolucionarios Goodwin (2001) estableció una relación curvilínea entre la cantidad de represión y los costos de embarcarse en acciones contenciosas. Así luego de cierto umbral de represión, los costos de protestar ya no pueden continuar aumentando para los grupos agraviados. Sin embargo, Brockett (2005) observó una relación diferente, más cercana a la de una "U" invertida. En su trabajo se explica que en regímenes autoritarios "semi-represivos", la protesta se vería facilitada cuando la represión se encuentra en su nivel mínimo, y en la medida en que el movimiento logre progresivamente aumentando los niveles de contención mayor cantidad de violencia represiva debería utilizar el régimen para superar el desafío popular. Bajo este argumento, los niveles de represión deben ser proporcionales al grado de contención alcanzado si es que el Estado espera tener éxito en la desarticulación de las acciones contenciosas. Por su parte Hess (2013) puso atención en la distribución de poder dentro del régimen para explicar cuando un movimiento de protesta sería más fácil de reprimir. En su trabajo observó que aquellos regímenes autoritarios descentrados políticamente evitaban de forma más eficiente la aparición de desafíos colectivos a gran escala, con ello el uso de la violencia para reprimir seria mucho menor en la medida en que los desafíos eran pequeños en número, fáciles de identificar, y restringidos a la comunidad local.

Igualmente, aquellos grupos que pretenden comprometerse en acciones colectivas que desafíen a un régimen autoritario deben plantearse el asunto de la violencia como un recurso posible dentro de sus repertorios. Como se discutió al final de este trabajo, los desafíos violentos y aquellos no-violentos tienen consecuencias directas sobre el régimen y sobre los oponentes, en particular en cuanto a los posibles resultados de la contienda política. Por ejemplo, la evidencia mostró un nivel de éxito avasallador en la consecución de sus objetivos para aquellos movimientos no-violentos por sobre aquellos que utilizaron métodos violentos. Esto parece ser así porque en el terreno de la violencia, el régimen usualmente tiene más recursos en términos de capacidad coercitiva. Sin embargo, una resistencia no-violenta que logre ser sostenible en el tiempo inevitablemente pondrá en un dilema al régimen respecto de que tipo de respuestas y estrategias debe desarrollar a fin de desarticular dicho desafío. Esto es así porque reprimir violentamente un movimiento no-violento puede producir un efecto contrario al deseado, deslegitimando al régimen y facilitando el aumento del apoyo a la causa de los oponentes. Debido a esto, es que parece ser que bajo un régimen autoritario no basta únicamente establecer diferencias conceptuales y analíticas entre acciones y/o campañas violentas y no-violentas, 
sino avanzar hacia una comprensión de las estrategias y las tácticas aún más sofisticada.

En suma, en este trabajo se trató la relación entre protesta contenciosa y política autoritaria. Las dimensiones de esta relación son múltiples y complejas, no obstante, se ha tratado de destacar los aspectos que parecen ser más relevantes en los enfoques conceptuales y teóricos que la literatura más reciente ha desarrollado. La evidencia empírica, así como las metodologías utilizadas demuestran que cada vez es más necesario volver sobre la interdisciplina para enfrentarse a problemas de esta envergadura, así como estar continuamente ir testeando las hipótesis y tensando los conceptos a partir de nuevos estudios de caso y comparados. En este sentido, con la sola excepción de Brockett y Almeida, la mayoría de los trabajos expuestos parecen haber olvidado a América Latina. Este continente se caracterizó por su política autoritaria, los constantes golpes de Estado, así como por ser testigo de dos de las revoluciones más importantes en México y en Cuba. En este sentido, los especialistas en América Latina han puesto su atención en los movimientos sociales democratizadores que emergieron a inicio de los noventa, mientras que los historiadores que han analizado la política contenciosa bajo las experiencias autoritarias del continente no han recurrido de forma sistemática a la literatura especializada expuesta en este trabajo. Esto no quiere decir que sus trabajos sean de menor calidad conceptual o explicativa, por el contrario, de lo que se tratar es de continuar tendiendo puentes entre disciplinas y áreas de investigación, a fin de ir mejorando los modelos explicativos, así como de revisitar interpretaciones que a la luz de nuevos enfoques permitirían una mejor comprensión de la historia, pero también de los procesos actuales.

Felipe Sánchez Barría (fasanchez@uc.cl) es candidato a Doctor en Sociología por la Pontificia Universidad Católica de Chile. Vinculación Institucional: Instituto de Sociología, UC, Santiago, Chile.

\section{Referencias}

Accornero, G., 2013. Contentious Politics and Student Dissent in the Twilight of the Portuguese Dictatorship: Analysis of a Protest Cycle. Democratization, 20(6), pp.1036-1055. DOI: 10.1080/13510347.2012.674367

,2016. Revolutionary or Mild Mannered? Social Movements and Social Movements Studies in Portugal. In O. Fillieule \& G. Accornero, eds. Social Movement Studies in Europe. The State of the Art. New York/Oxford: Berghahn Books.

Almeida, P., 2003. Opportunity Organizations and Threat-Induced Contention: Protest Waves in Authoritarian Settings. American Journal of Sociology, 109(2), pp.345-400. DOI: 10.1086/378395 2008. Waves of Protest. Popular Struggle in El Salvador, 1925-2005. Minneapolis: University of Minnesota Press.

Beissinger, M., 2002. Nationalist Mobilization and the Collapse of Soviet State. New York: Cambridge University Press. DOI: $10.1017 / \mathrm{CBO} 9781107415324.004$

Boudreau, V., 2005. Precarious Regimes and Matchup Problems in the Explanation of Repressive Policy. In C. Davenport; H. Johnston \& C. Mueller, eds. Repression and Mobilization. Minneapolis: University of Minnesota Press.

Brady H.; Verba S. \& Schlozman, K.L., 1995. Beyond SES: A Resource Model of Political Participation. The American Political Science Review, 89(2), pp.271-294. DOI: 10.2307/2082425

Brownlee, J., 2007. Authoritarianism in an Age of Democratization. Cambridge, UK: Cambridge University Press.

Brockett, C., 2005. Political Movements and Violence in Central America. Cambridge, UK: Cambridge University Press.

Chambers, S. \& Kopstein, J., 2001. Bad Civil Society. Political Theory, 29(6), pp.837-865. DOI: 10.1177/0090591701029006008

Chenoweth, E. \& Shock, K. 2015. Do the Contemporaneous Armed Challenges affect the Outcomes of Mass Nonviolent Campaigns. Mobilization: An International Quarterly, 2(4), pp.427-451. DOI: 10.17813/1086-671X-20-4-427

Chenoweth, E. \& Stephan M., 2011. Why Civil Resistance Works: The Strategic Logic of Nonviolent Conflict. New York: Columbia University Press.

Dalton, R.; Van Sickle, A. \& Weldon, S., 2010. The Individual-Institutional Nexus of Protest Behaviour. British Journal of Political Science, 40(1), pp.51-73. DOI: 10.1017/S000712340999038X

Davenport C., 2005. Repression and Mobilization: Insights from Political Science and Sociology. In C. Davenport; H. Johnston \& C. Mueller, eds. Repression and Mobilization. Minneapolis: University of Minnesota Press.

della Porta, D. \& Diani, M., 2006. Social Movements: An Introduction. Malden, MA: Blackwell.

DeNardo, J., 1985. Power in Numbers. The Political Strategy of Protest and Rebellion. New Jersey: Princeton University Press. 
Derby, L., 2009. The Dictator's Seduction: Politics and the Popular Imagination in the Era of Trujillo. Durham: Duke University Press.

Encarnación, O., 2002. Venezuela's “Civil Society Coup”. World Policy Journal, 19(2), pp.38-48. DOI: $10.1215 / 07402775-2002-3005$

Fillieule, O., 2005. Requiem pour un concept: Vie et mort de la notion de structure des opportunités politiques. In G. Dorronsoro, ed. La Turquie conteste. Mobilisations sociales et régime sécuritaire. Paris: CNRS.

Francisco, R., 2006. The Dictator's Dilemma. In C. Davenport; H. Johnston \& C. Mueller, eds. Repression and Mobilization. Minneapolis: University of Minnesota Press.

Goodwin, J., 2001. No Other Way Out. States and Revolutionary Movements, 1945-1991. Cambridge, UK: Cambridge University Press.

Hess, S., 2013. Authoritarian Landscapes. Popular Mobilization and the Institutional Sources of Resilience in Nondemocracies. New York: Springer.

Jasper, J., 2015. Introduction. Playing the Game. In J. Jasper \& J.W. Duyvendak, eds. Players and Arenas. The Interactive Dynamics of Protest. Amsterdam: Amsterdam University Press.

Jenkins, C.; Jacobs, D. \& Agnone, J., 2003. Political Opportunities and African-American Protest, 1948-1997. American Journal of Sociology, 109(2), pp.277-303. DOI: 10.1086/378340

Kricheli, R.; Livne, Y. \& Magaloni, B., 2011. Taking to the Streets. Theory and Evidence of Protest under Authoritarianism. APSA 2010 Annual Meeting Paper. Washington (DC).

Koopmans, R., 2004. Movements and Media: Selection Processes and Evolutionary Dynamics in the Public Sphere. Theory and Society, 33(3-4), pp.367-391. DOI: 10.1023/b:ryso.0000038603.34963.de

Levitsky, S. \& Way, L., 2010. Competitive Authoritarianism. Hybrid Regimes after Cold War. Cambridge, UK: Cambridge University Press.

Linz, J., 1975. Totalitarian and Authoritarian Regimes. In F. Greenstein \& N. Polsby, eds. Handbook on Political Science. Reading: Addison-Wesley Educational Publishers.

Linz, J. \& Stephan, A., 1996. Problems of Democratic Transition and Consolidation: Southern Europe, South America, and Post-Communist Europe. Baltimore: Johns Hopkins University Press.

Mason, T.D. \& Krane, D., 1989. The Political Economy of Death Squads: Toward a Theory of the Impact of State-Sanctioned Terror. International Studies Quarterly, 33(2), pp.175-198. DOI: 10.2307/2600536

McAdam, D.; McCarthy, J. \& Zald, M., 1999. Movimientos sociales: perspectivas comparadas. Madrid: Istmo.

McAdam, D.; Tarrow, S. \& Tilly, C., 2003. Dinámica de la contienda política. Barcelona: Hacer.

McCarthy, J. \& Zald, M., 1977. Resource Mobilization and Social Movements: A Partial Theory. The American Journal of Sociology, 82(6), pp.1212-1241. DOI: 10.1086/226464

McGlinchey, E., 2009. Central Asian Protest Movements: Social Forces or State Resources? In A. Wooden \& C. Stefes, eds. The Politics of Transition in Central Asia and the Caucasus. London: Routledge.

Muller, E. \& Weede, E., 1990. Cross-National Variation in Political Violence. A Rational Action Approach. The Journal of Conflict Resolution, 34(4), pp.624-651.DOI: 10.1177/0022002790034004003

Menke, B.; White, M. \& Carey, W.L., 2002. Profissionalização da polícia: em busca de excelência ou de poder político? In J.R. Greene, ed. Administração do trabalho policial: questões e análises. São Paulo: Editora da Universidade de São Paulo.

Nepstad, S., 2011. Nonviolent Revolution. New York: Oxford University Press.

Norris, P., 2002. Democratic Phoenix: Reinventing Political Activism. New York: Cambridge University Press.

O’Donnell, G. \& Schmitter, P., 1988. Transiciones desde un gobierno autoritario. Buenos Aires: Paidos.

Oliver, P., 1989. Bringing the Crowd Back In. The Non-Organizational Elements of Social Movernents. In L. Kriesberg, ed. Research in Social Movements, Conflict and Change. V. 11. Greenwich: JAI Press.

Opp, K.D., 2009. Theories of Political Protest and Social Movements: A Multidisciplinary Introduction, Critique, and Synthesis. London: Routledge.

Osa, M., 2003. Solidarity and Contention. Networks of Polish Opposition. Minneapolis: University of Minnesota Press.

Oxhorn, P., 1995. Organizing Civil Society: The Popular Sectors and the Struggle for Democracy in Chile. University Park: Pennsylvania State University Press.

Pearlman, W., 2011. Violence, Nonviolence, and the Palestinian National Movement. New York: Cambridge University Press.

Schedler, A., 2013. The Politics of Uncertainty: Sustaining and Subverting Electoral Authoritarianism. Oxford: Oxford University Press.

Schmitter, P., 1993. Some Propositions about Civil Society and the Consolidation of Democracy. Serie de Ciencia Politica, 10. Viena: Institut für Höhere Studien.

Schock, K., 2005. Unarmed Insurrections. People Power Movements in Nondemocracies. Minneapolis/London: University of Minnesota Press.

Snow, D. et al., 1986. Frame Alignment Processes, Micromobilization, and Movement Participation. American Sociological Review, 51(4), pp. 464-481. DOI: 10.2307/2095581

Staggenborg, S., 1998. Social Movement Communities and Cycles of Protest: The Emergence and Maintenance of a Local Women's Movement. Social Problems, 45(2), pp.180-204. DOI: 10.2307/3097243

Stephan, M.J. \& Chenoweth, E., 2008. Why Civil Resistance Works: The Strategic Logic of Nonviolent Conflict. International Security, 33(1), pp.7-44. DOI: 10.1162/isec.2008.33.1.7

Svolik, M., 2012. The Politics of Authoritarian Rule. Cambridge, UK: Cambridge University Press. 
Valdivia, V., 2003. El Golpe después del Golpe. Leigh vs. Pinochet. Santiago: LOM.

Weldon, S. \& Dalton, R., 2014. Democratic Structures and Democratic Participation: The Limits of Consensualism Theory. In J. Thomassen, ed. Elections and Democracy. Representation and Accountability. Oxford: Oxford University Press.

Welzel, C.; Inglehart, R.F. \& Deutsch, F., 2005. Social Capital, Voluntary Associations and Collective Action: Which Aspects of Social Capital Have the Greatest "Civic" Payoff? Journal of Civil Society, 1(2), pp.121-146. DOI: $10.1080 / 17448680500337475$

Tarrow, S., 1993. Cycles of Collective Action: Between Moments of Madness and the Repertoire of Contention. Social Science History, 17(2), pp.281-307. DOI: 10.2307/1171283

, 1998. El Poder en Movimiento: Los movimientos sociales, la acción colectiva y la política. Madrid: Alianza.

Tilly C., 2001. The Politics of Collective Violence. New York: Cambridge University Press. 2006. Regimes and Repertoires. Chicago: The Chicago University Press.

Tilly, C. \& Tarrow, S., 2015. Contentious Politics. 2a ed. Oxford: Oxford University Press.

\section{The Politics of Protest in Authoritarian Regimes. A critical review}

ABSTRACT Introduction: Through a critical review of recent literature, the essay explores the relationship between contentious protest and authoritarian regimes and examines the dynamics and consequences that emerge during the political conflict. Methods: three elements that scholars have identified as key in this relationship are discussed: the political opportunities and threats, cycles of protest and the sustainability of the social movements, and the relationship between state violence and collective action. Results: Recurrence of protest in repressive regimes shows the ability of civil society to articulate these contentious actions. Discussion: However, paths and results depend, on the one hand, on the political features of the regime and on the competence of the government to respond to collective challenges; and, on the other hand, on the ability of opponents to mount cycles of protest that are dense in participation during a significant period, the type of tactics adopted, and the adaptability and resilience to the State violence.

KEYWORDS: protest; authoritarianism; contentious politics; political regime; repression.

This is an Open Access article distributed under the terms of the Creative Commons Attribution Non-Commercial License which permits unrestricted non-commercial use, distribution, and reproduction in any medium provided the original work is properly cited. 